\title{
Status and conservation of the giant muntjac Megamuntiacus vuquangensis, and notes on other muntjac species in Laos
}

\author{
R. J. Timmins, T. D. Evans, Khamkhoun Khounboline and \\ Chainoi Sisomphone
}

The large-antlered, or giant, muntjac Megamuntiacus vuquangensis was described from Vietnam in 1994 and found concurrently in the Annamite Mountains and nearby hill ranges of central and southern Laos. The northerly and southerly range limits are still unknown. It may occupy a wide range of habitats and is found sympatrically with the common muntjac Muntiacus muntjak. Another muntjac species, the taxonomic affinity of which is as yet undetermined, was recently discovered to occur within its range. The large-antlered muntjac is probably not threatened with extinction in the near future, but in view of its restricted range and threats from habitat degradation and hunting, it should be classified as Vulnerable in the Red Data Book. Its future in Laos is largely dependent on the recently created protected-areas system to maintain large tracts of habitat and reduce hunting pressure.

\section{Introduction}

Megamuntiacus vuquangensis, the giant muntjac, was discovered in Vietnam and Laos in 1994. It was described from the Vu Quang Nature Reserve in early 1994 (Tuoc et al., 1994) and was found concurrently in central Laos (Duckworth et al., 1994; Evans and Timmins, 1995). This paper presents current information on its distribution, habitat and conservation in Laos based on wildlife surveys conducted between 1992 and 1996. Recent information on all other species of muntjac known from Laos is also given.

The giant muntjac shares almost all the characteristics listed by Groves and Grubb (1990) for the genus Muntiacus, which includes all other muntjacs. The genus Megamuntiacus was created largely on the basis of its distinctive antlers and pedicles (Tuoc et al., 1994), a justification that might not be valid (Schaller and Vrba, 1996; Timmins et al., unpubl. data). The common, or Indian, muntjac Muntiacus muntjak is found throughout much of the Indo-Malayan realm (Corbet and Hill, 1992), and is distributed widely in Laos, including throughout the entire known range of the giant muntjac. In addition to these species, a third, smaller species of muntjac, whose identity remains undetermined, has been found within the range of the giant muntjac (Timmins, 1996). The one other species known from Laos, Roosevelt's muntjac Muntiacus rooseveltorum, is known from a single, immature, male specimen collected on 16 May 1929 from Ban Muangyo $\left(21^{\circ} 30^{\prime} \mathrm{N}, 101^{\circ} 50^{\prime} \mathrm{E}\right)$ in the far north (Osgood, 1932). There is no recent information on this species. It is possible that other species are present; the Gongshan muntjac Muntiacus gongshanensis has been reported from areas of southern Yunnan, China, relatively close to Laos (Grubb, 1977; Groves and Grubb, 1990).

\section{Survey methods}

An extensive series of wildlife surveys has been carried out in Laos, east and south of Vientiane since 1992 (Thewlis et al., in press). 
Observations were recorded from diurnal and nocturnal surveys on foot or by small boat (e.g. Duckworth et al., 1994; Thewlis et al., 1996). Muntjacs were the most commonly observed ungulates, yet sighting frequency was less than one per observer-month, including many individuals unidentified because of fleeting or poor views. Most field information on muntjacs came from tracks and calls, neither of which can be identified to species.

Most information came from the examination of remains, principally antlers and pedicles attached to partial skulls found in villages and at hunters' campsites. Antlers of the giant muntjac are easily distinguished from those of other muntjac species (Table 1; Figure 1). Indications of abundance were derived from the relative proportions of trophies seen of different species. Interviews with villagers were undertaken frequently but the results were not used in this analysis for several reasons. In some villages, examination of trophies and other material was hampered by people's apprehension or disinterest. Information from interviews with hunters was confounded by the variable local nomenclature, where different names can be given to the sexes, and to young and old animals. In many villages with trophies of both species, residents referred to a large, dark form and a small, reddish form, but were unable to identify individual trophies of the giant muntjac. They assigned these to both large and small forms, and did the same for trophies of the common muntjac. In some villages with trophies of both species, local people recognized only a single form. Desai and Lic Vuthy (1996) also found that in Cambodia, villagers could not distinguish between the two species. The uncertainties surrounding verbal information, vagueness of locality descriptions and in many cases simply the villager not remembering, made it very difficult to determine the precise locality or habitat type from which a trophy had come.

\section{Field recognition}

Given the paucity of information on all but the common muntjac, any muntjac observations from the region could be potentially valuable. The features in Table 1 represent the most useful field characters, which should be noted during any muntjac field observations. Examination of museum specimens suggests that these features are relatively conservative in animals of a taxon from the same area. The features are provisional, and are represented here to provide a basis and guide for fieldworkers to expand upon.

The antlers and pedicles are the most easily identifiable characters of the different species (Figure 1 and Table 1), allowing trophies to be identified easily, with some exceptions. Roosevelt's muntjac is predicted to have small antlers, either like those of the small undetermined species or like small antlers of the common muntjac, but its pedicles are short like those of the small undetermined species. Furthermore, trophies of the common muntjac are difficult to separate from Fea's muntjac Muntiacus feae or the Gongshan muntjac. It is these species that any additional species in Laos are most likely to resemble.

The uniformity of pelage and lack of contrastingly dark tail make the common muntjac relatively easy to identify in the field. Extreme caution should be used when identifying any dark-tailed animals, and perhaps at present only male giant muntjacs or males of the small undetermined species in which the pedicles and antlers, other pelage and tail features are seen, should be positively identified. Differences in body size are not sufficient to be a reliable field character in any of the species known from Laos. In two areas of Laos, muntjacs with long blackish tails contrasting with the hind quarters were observed. These observations fit none of the species in Table 1, but suggest either further taxa or greater variability than is presented here in the pelage of the taxa known from Laos.

\section{Distribution and ecology}

Currently, the known range of the giant muntjac corresponds with the furthest points surveyed in central and southern Laos $\left(15^{\circ} 25^{\prime} \mathrm{N}\right.$ to $\left.18^{\circ} 40^{\prime} \mathrm{N}\right)$, principally in the Annamite 
Mountains, which form the border with Vietnam (Figure 2). The species has been found in Cambodia (Desai and Lic Vuthy, 1996), and in Vietnam it has been found as far south as the Dalat Plateau in central Annam (c. $12^{\circ} \mathrm{N}$; Ha Dien Duc, pers. comm.), considerably further south than the records from Laos.

The most extensive forests in this range lie between $17^{\circ} 30^{\prime}$ and $19^{\circ} 10^{\prime} \mathrm{N}$. The Nakai-Nam Theun National Biodiversity Conservation Area (NBCA) may be both a centre of the giant muntjac's Lao distribution and its population's core area. Nakai-Nam Theun NBCA is the only site where trophies of the largeantlered muntjac outnumbered those of the common muntjac (by a ratio of $c .2: 1$; more than 50 giant muntjac trophies were found in this area). Given the frequency of muntjac tracks and calls, it seems probable that the species is relatively common in this area. In other areas where both species occur, there were typically less than half as many giant
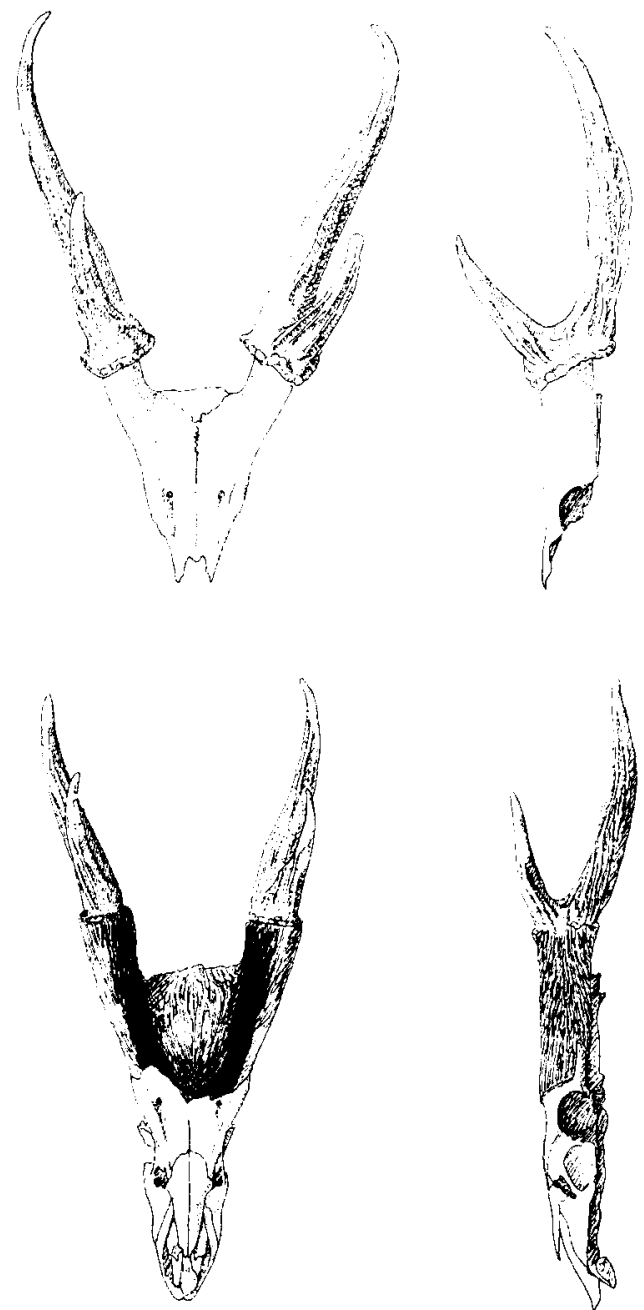

M. vuquangensis

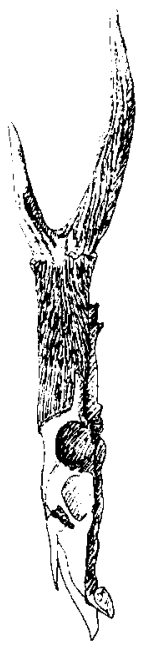

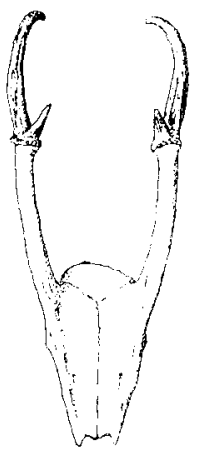

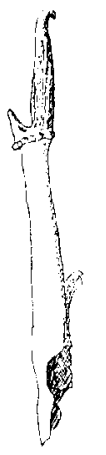

$E_{5}^{0} \mathrm{~cm}$
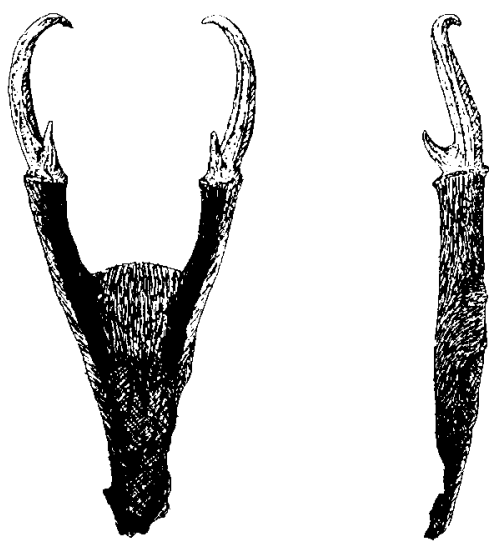

M. muntjak

Figure 1. Line drawings of giant muntjac Megamuntiacus vuquangensis and common muntjac Muntiacus muntjak trophies.

(C) $1998 \mathrm{FFI}$ Oryx, $32(1), 59-67$ 


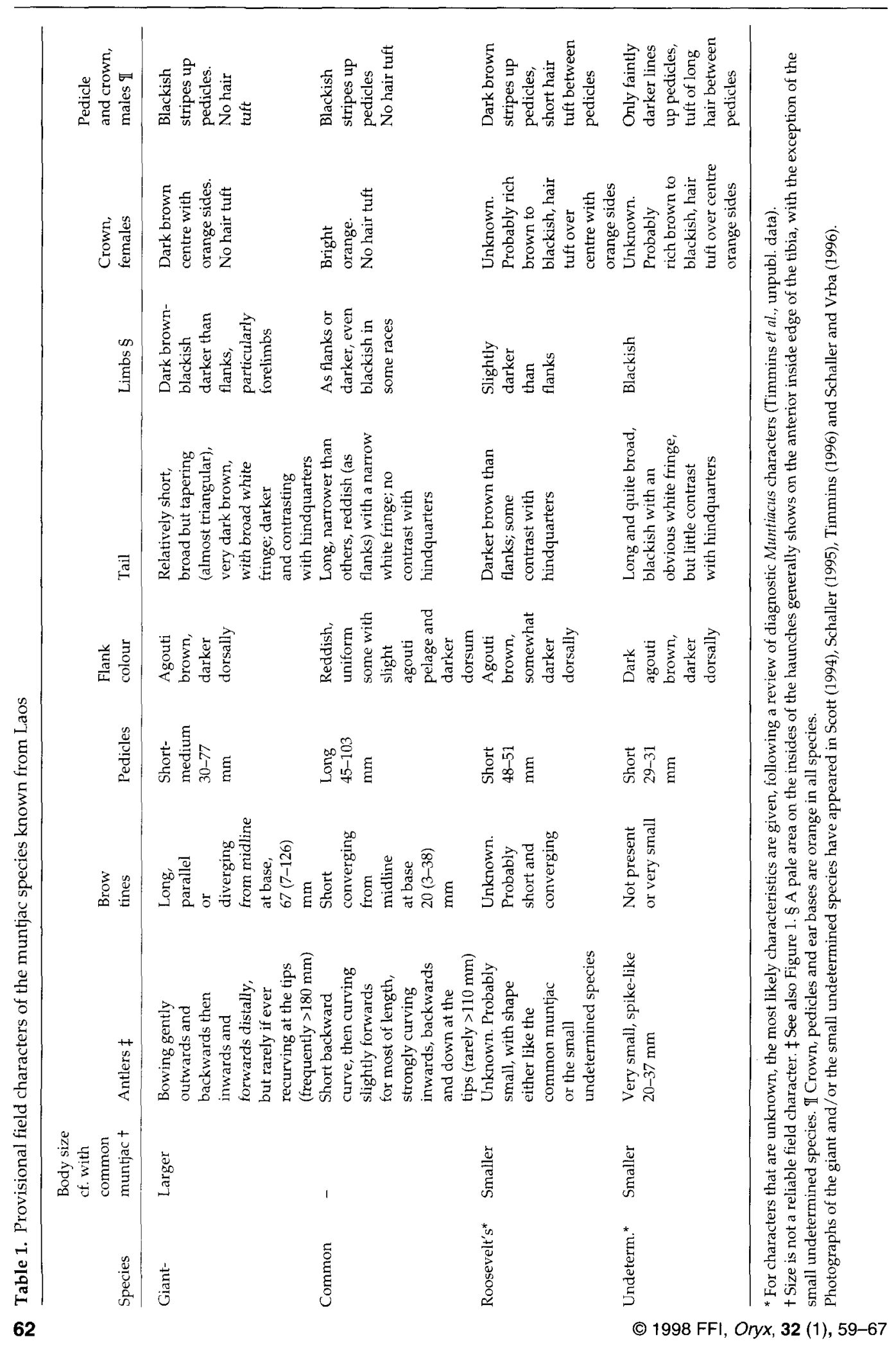


muntjac trophies found as those of the common muntjac.

The distribution records of the giant muntjac suggest that it predominates in evergreen forests in the east associated with the Annamite Mountains, of which Phou Xang $\mathrm{He}$, Xe Bang Nouan and Nam Kading NBCAs are all outliers. Three sightings of the giant muntjac were in varying habitats of wet evergreen forest at $800 \mathrm{~m}$, drier evergreen forest at $950 \mathrm{~m}$ (provisional record), and in a mosaic of fairly open mixed pine/semi-evergreen secondary forest at about $520 \mathrm{~m}$ (provisional record). There are indications based on trophy ratios that the giant muntjac is scarcer than the common muntjac in degraded habitats, but this requires confirmation. It is probably scarce or absent in the drier, semi-evergreen and mixed deciduous forests associated with the Mekong Plains.

The giant muntjac has a wider distribution in Laos than does the saola Pseudoryx nghetinhensis (another recently described ungulate from the region), which is also restricted to the Annamite Mountains. The saola appears to be predominantly associated with wetevergreen forests under the influence of the winter north-east monsoon, a habitat that is relatively restricted on the western Lao side of the Annamites (Timmins, in press). Evidence for the small, undetermined muntjac species has been found in only three areas: two sites over $1000 \mathrm{~m}$ and a third above $500 \mathrm{~m}$ in an area of predominantly wetevergreen forest, suggesting that it may have a relatively restricted range, similar to that of the saola.

Common muntjacs have been seen on recent surveys in mixed deciduous, semi-evergreen, dry evergreen and wet evergreen forests, field edges and scrub from 80 to at least $1100 \mathrm{~m}$, and appear to be widespread throughout much of Laos, except in the most open and very heavily hunted habitats. Given the observed habitat overlap, the common muntjac is probably closely sympatric with the giant muntjac over much of its range. Both species are presumably sympatric in some areas with. the small undetermined muntjac species.

\section{Threats and conservation}

Hunting is a considerable problem throughout Laos. Muntjacs are frequently taken, probably because their meat is highly regarded and because common muntjacs are abundant relative to larger quarry such as the sambar Cervus unicolor and wild cattle Bos spp. Much of the meat is eaten in villages, but there is a ready market for wider distribution in towns. The main capture methods are snaring at gaps in long brush fences, nocturnal hunting with head-lamps, and hunting with dogs during the day. A total ban on hunting of the giant muntjac or the small, undetermined species would be unrealistic, in part because this would also necessitate limits on the hunting of the very similar common muntjac.

Slash-and-burn agriculture practised by the many ethnic groups is a severe threat to the Annamite Mountain forests. Shifting cultivation in Laos is estimated to claim 100,000 ha of primary forest and 300,000 ha of secondary forest a year (Lao government estimate, quoted by Fujisaka, 1991). The Hmong, an ethnic group, which has been moving into central Laos (including into the Naki-Nam Theun NBCA area) from the north, is of particular concern. The Hmong traditionally practise slash-and-burn cultivation and are very effective hunters. Although the government has a policy of curbing shifting cultivation, both habitat degradation and hunting pressure are likely to increase in view of the country's high population growth rate of 2.4 per cent (National Statistical Centre, 1995). Current commercial developments in central Laos, particularly hydroelectric power projects and logging operations, will cause rapid habitat losses and open formerly remote areas to possible settlement and increased hunting pressure (Evans and Timmins, 1995; Thewlis et al., in press). Common muntjac populations appear to be relatively tolerant of hunting pressure and forest degradation, but it should not be assumed that this is the case for the other muntjac species.

The long-term survival of the giant muntjac is likely to come to depend on the populations within protected areas. These areas are 


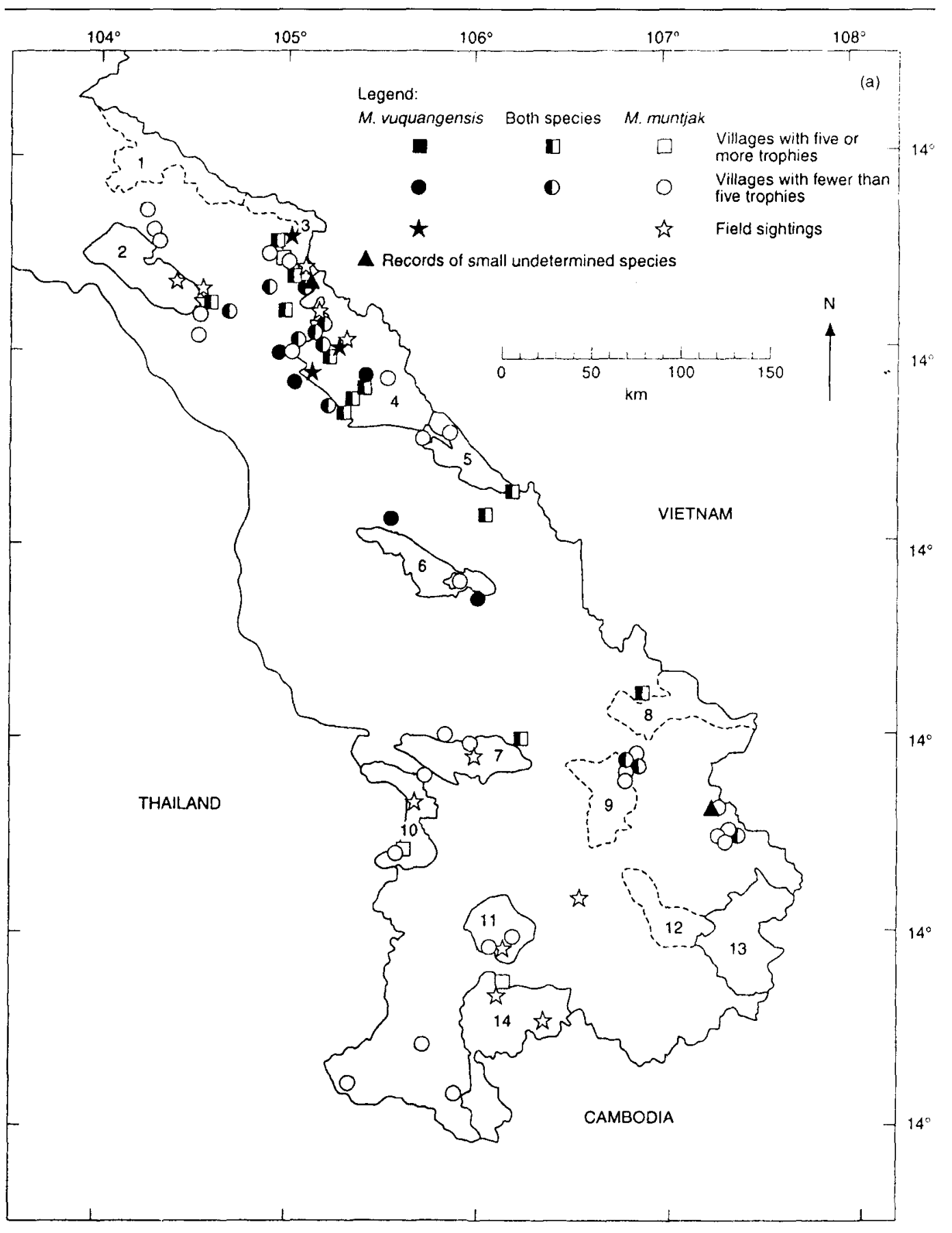

Figure 2(a). Central and southern Laos: protected areas and distributional records of Megamuntiacus vuquangensis and Muntiacus muntjak. National Biodiversity Conservation Areas and Proposed Protected Areas: 1, Nam Chuan PPA; 2, Nam Kading NBCA; 3, Nakai-Nam Theun proposed northern extension; 4, Nakai-Nam Theun NBCA; 5, Hin Namnu NBCA; 6, Phou Xang He NBCA; 7, Xe Bang Nouan NBCA; 8, Xe Sap PPA; 9, Phou Theung PPA; 10, Phou Xiang Thong NBCA; 11, Dong Hua Sao NBCA; 12, Phou Kathong PPA; 13, Dong Amphan NBCA; 14, Xe Pian NBCA 


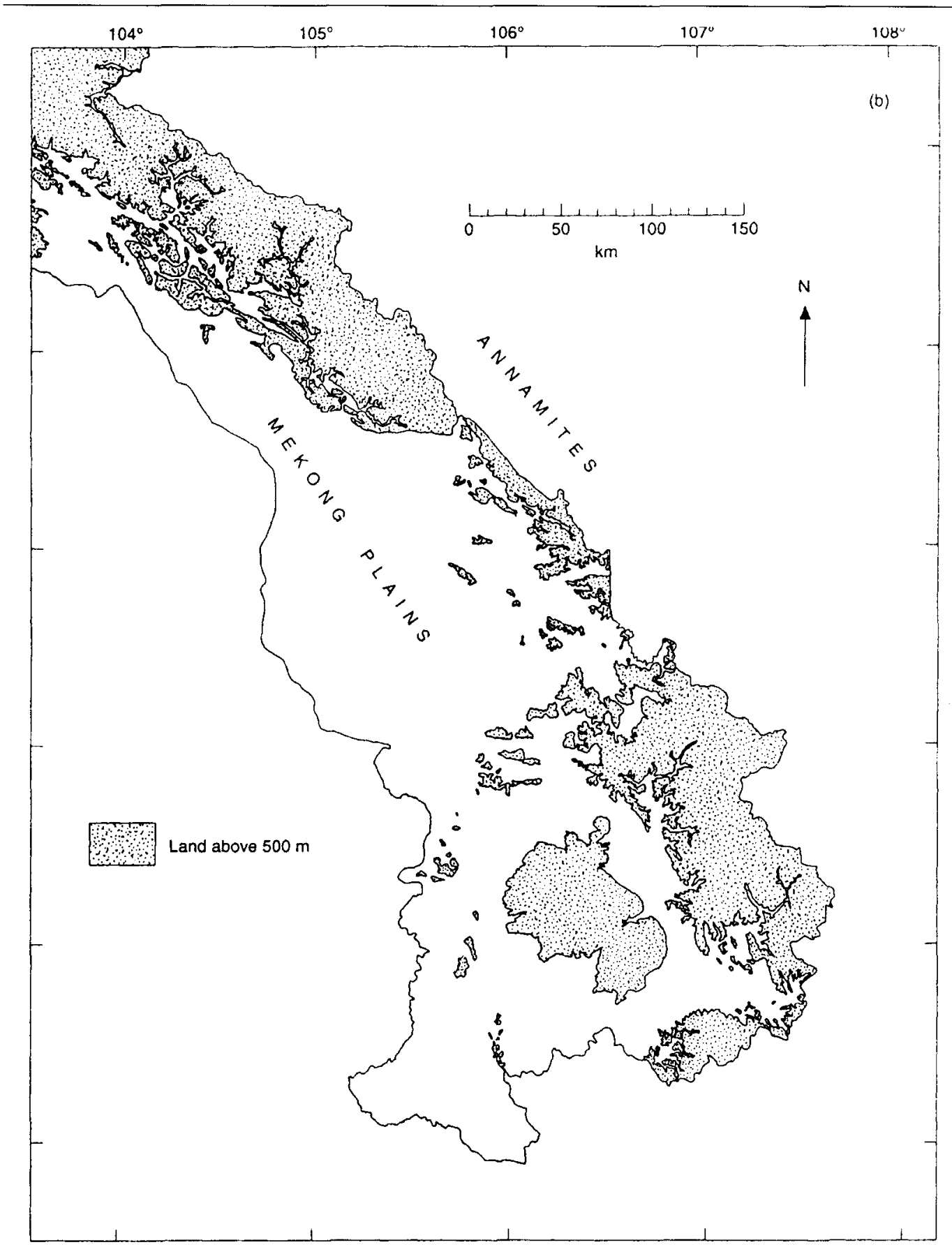

Figure 2(b). Central and southern Laos: the 500-m contour topographically delimiting the Annamite mountain and Mekong plains areas.

Note: during recent surveys evergreen forest has been found to predominate in areas above $500 \mathrm{~m}$, with areas below this altitude supporting predominantly semi-evergreen, mixed deciduous or dry dipterocarp forests; the exception is Phou Xang He NBCA and areas to the east of this, where extensive evergreen forests were found at lower altitudes. 
currently protected mainly by their large size, inaccessibility and inhospitable terrain. Further protection is hampered by the inexperience within the newly created government conservation strategy and infrastructure, together with shortages of funding and trained manpower. Berkmüller et al. (1995) discussed the management strategy of these areas. Resisting further habitat loss and reserving restricted areas with controlled hunting are of primary importance. The amelioration of threats from commercial development depends on commitment and action from the top level of the Lao Government. Transboundary reserves have been proposed and should be a priority for implementation in the Annamite Mountain border regions, even if co-operative management of such areas is not possible.

Laos may hold a large part of the giant muntjac's world population and has a major role to play in its conservation. Further surveys are needed to clarify the number of muntjac species in Laos and their distributions. Investigation into habitat use and the response of muntjac populations to human hunting pressure are also needed. Meanwhile, the giant muntjac merits inclusion in the IUCN Red List. The Lao population should be listed as Vulnerable under criteria A2c,d (IUCN Species Survival Commission, 1994), because a future decline of at least 20 per cent in 10 years is likely, due to increasing hunting pressure combined with rapid clearance of habitat. The same is likely to be true in Vietnam, where the species faces similar threats, compounded by a higher human population density than in Laos (Collins et al., 1991). Given a more restricted range for the small undetermined species, it too is probably Threatened using the same criteria.

\section{Acknowledgements}

We are indebted to the Centre for Protected Areas and Watershed Management of the Department of Forestry in Vientiane, in particular to $\mathrm{Mr}$ Chanthaviphone Inthavong, $\mathrm{Mr}$ Saleumsy Phithayaphone, Mr Sivanavong Siwathvong, Mr Venevongphet and Klaus Berkmüller, and provincial and district forestry office staff in the areas where we worked, for their considerable help and assistance in facilitating the fieldwork. Bounhom Sounthala, Bounsou Souan, Somphong Souliyavong and Sukotha Vannalat, our field companions, are also warmly thanked. Some of the distribution records were provided by George Schaller, William Robichaud and William Leacock. Help and advice were also received from the staff of the Natural History Museum (London), Peter Arctander, Bill Bleisch, Mike Bruford, Shanthini Dawson, Professor Ha Dien Duc, William Duckworth, John and Angela Evans, Colin Groves, Peter Grubb, Tomas Jonsson, John MacKinnon, Alan Rabinowitz, Nancy Ruggeri, Roger Safford, Gill Timmins, the manager of the PhouDoi II Hotel, Ban Lak (20) and the residents of the study areas. Fieldwork was funded from various sources, notably the Wildlife Conservation Society and IUCN-The World Conservation Union.

\section{References}

Berkmüller, K., Evans, T.D., Timmins, R.J. and Venevongphet. 1995. Recent advances in nature conservation in the Lao PDR. Oryx, 29, 253-260.

Collins, N.M., Sayer, J.A. and Whitmore, T.C. 1991. The Conservation Atlas of Tropical Forests: Asia and the Pacific. Simon and Schuster, New York.

Corbet, G.B. and Hill, J.E. 1992. The Mammals of the Indo-Malayan Realm: a Systematic Review. Oxford University Press, Oxford.

Desai, A. and Lic Vuthy. 1996. Status and Distribution of Large Mammals in Eastern Cambodia.: Results of the First Foot Surveys in Mondulkiri and Rattanakiri Provinces. IUCN/FFI/WWF Large Mammal Conservation Project, Phnom Penh.

Duckworth, J.W., Timmins R.J., Thewlis, R.M., Evans, T.D. and Anderson, G.Q.A. 1994. Field observations of mammals in Laos. Natural History Bulletin of the Siam Society, 42, 177-205.

Evans, T.D. and Timmins, R.J. 1995. News from Laos. Oryx, 29, 3-4.

Fujisaka, S. 1991. A diagnostic survey of shifting cultivation in northern Laos: targeting research to improve sustainability and productivity. Agroforestry Systems, 13, 95-109.

Groves, C.P. and Grubb, P. 1990. Muntiacidae. In Horns, Pronghorns and Antlers-Evolution, Morphology, Physiology and Social Significance (eds G. A. Bubenik and A. B. Bubenik), pp. 134-168. Springer-Verlag, New York.

Grubb, P. 1977. Notes on a rare deer, Muntiacus feai Ann. Mus. Civ. Stor. Nat. Genoa, 81, 202-207.

IUCN Species Survival Commission. 1994. IUCN Red List Categories. IUCN, Gland, Switzerland.

National Statistical Centre. 1995. Lao Census 1995, Preliminary Report 2 (Results on the Province and District Level). Unpublished report by the 
Committee for Planning and Co-operation, Government of Lao PDR, Vientiane.

Osgood, W.H. 1932. Mammals of the KelleyRoosevelt and Delacour Asiatic Expeditions. Field Museum of Natural History Publications 312. Zoological Series, 18 (10), 192-339.

Schaller, G.B. 1995. Conservation Hotline: an unfamiliar bark. Wildlife Conservation (June 1995), 98, 8. Wildlife Conservation Society, New York.

Schaller, G.B. and Vrba, E.S. 1996. Description of the giant muntjac (Megamuntiacus vuquangensis) in Laos. Journal of Mammalogy, 77 (3), 675-683.

Scott, K. 1994. One small step for muntjac: new creatures seen alive for the first time. $B B C$ Wildlife, 10 (8), 10.

Thewlis, R.M., Duckworth, J.W., Anderson, G.Q.A., Dvorak, M., Evans, T.D., Nemeth, E., Timmins, R.J. and Wilkinson, R.J. 1996. Ornithological records from Laos, 1992-1993. Forktail, 11, 47-100.

Thewlis, R.C.M., Timmins, R.J., Evans, T.D. and Duckworth, J.W. In press. A preliminary assessment of the status and conservation needs of threatened birds in Laos. Bird Conservation International.

Timmins, R.J. 1996. Another muntjac materializes: more mammal finds in Laos. BBC Wildlife, 14 (3), 22-23.

Timmins, R.J. In press. Lao Country account for the saola. In The Antelope Action Plan (ed. D. Mallon). IUCN Species Survival Commission.

Tuoc, D., Dung, V.V., Dawson, S. Arctander, P. and MacKinnon, J. 1994. Introduction of a new large mammal species in Viet Nam. Science and Technology News. Forest Inventory and Planning Institute, Ministry of Forestry, Hanoi, Viet Nam. (In Vietnamese.)

Rob Timmins, The Wildlife Conservation Society, PO Box 6712, Vientiane, Lao PDR (address for correspondence: 25 Cradley Road, Cradley Heath, Warley, West Midlands B64 6AG, UK).

Tom Evans, 11a Yeoman Lane, Bearsted, Maidstone, Kent ME14 4BX, UK.

Khamkhoun Khounboline, Centre for Protected Areas and Watershed Management, Department of Forestry, PO Box 2932, Vientiane, Lao PDR.

Chainoi Sisomphone, Centre for Protected Areas and Watershed Management, Department of Forestry, PO Box 2932, Vientiane, Lao PDR.

Received 26 November 1996

Accepted 23 May 1997 